\title{
The Effect of Online Peer Feedback on the Academic Writing Ability of Iranian EFL Learners
}

\author{
Mohammad Reza Moradi \\ Faculty member of Payame Noor University \\ Dep. of English, Payame Noor University, Tehran, Iran \\ Tel: 98-916-341-9313 E-mail: r_mohammedmoradi@yahoo.com
}

\author{
Zahra Karimpour \\ E-mail: z_karimpour@yahoo.com
}

Received: October 26, 2011 Accepted: November 4, $2011 \quad$ Published: April 1, 2012

doi:10.5539/ies.v5n2p113 URL: http://dx.doi.org/10.5539/ies.v5n2p113

\begin{abstract}
This paper reports an exploratory study of 60 English as a foreign language (EFL) student's experiences of online peer feedback in an essay writing course at Islamic Azad University, Dezful Branch. They were required to comment on their peers' writing essays using the checklist to whom had been made available, but in different ways. The groups were required to self-assess their own writing piece, and share it with the other groups, either in offline or online forms and, subsequently, assess the other groups' essays in light of the criteria in the checklist and let them know about their comments. The performance of the two groups was, subsequently, compared using the t-test statistical analysis. It indicated that there is not any significant difference between the performances of the online and offline groups.
\end{abstract}

Keywords: Peer feedback, Online, Offline, Essay

\section{Introduction}

Feedback is one of the essential elements in the writing classroom. With its two forms, teacher and peer feedback can help students modify their essays to produce better later drafts. Peer commenting on each other's writing has been an important and useful instructional process in writing classes. With the development of information technology, the traditional written feedback has taken a new dimension. As a digital written form, student commentary can be transmitted electronically without the logistical complications of copying and distributing papers (Kemp, 2003; Tannacito \& Tuzi, 2002). Such feedback can be in the form of synchronous chat system interactions, asynchronous email, and bulletin-board postings. These technologies are becoming popular in university writing classes.

Central concern is how such e-feedback differs from traditional feedback to affect student' commenting behaviors and the quality of revision it generates. Asynchronous discussions are those that take place without participants being together physically or virtually at the same time. Synchronous discussions require all participants to be connected at the same time, either physically or via a communication channel. Research has shown that while both synchronous and asynchronous communications have their places in the online classroom, adult learners prefer asynchronous communication for its flexibility and the perception that asynchronous communication allows more time for reflective thinking.

With the emergence of computers in language teaching and learning, some second language writing (SLW) teachers started to consider integrating the use of computers in generating electronic teacher and peer feedback in an attempt to overcome these problems.

With the growth of Information Technology (IT), one of the areas which has adopted this new instrument is teaching on the whole and teaching of foreign languages in particular. According to Jones (2000), "the electronic resources instructors have available today, provide myriad opportunities for making texts more comprehensible to students" (p.11). Thus, shedding more light on the effectiveness of this potentially powerful device seems to be necessary.

Although CALL has not reached the stage of normalization, that is the process by which technology becomes 
invisible in the society, in language teaching profession hitherto (Box, 2003), the pace of this process is both slow and fast among countries of the world. Unfortunately, Iran is one of the countries in which such a process occurs almost very slowly and the use of computers in language teaching is not prevalent. Therefore, through uncovering the potential benefits of computers in language teaching, the normalization process of this assistant tool is thought to be accelerated in our country. So, this study aims to answer this question. To what extent do online or offline feedbacks improve the essay writing ability of Iranian EFL learners?

\section{Review of Related Literature}

The interaction in virtual mode, and by extension peer feedback, has some advantages. It releases the interlocutors from many drawbacks to face-to-face interactions such as students with bad breath, uncomfortable and vague situations. On the other hand, the fact that the interlocutors cannot see each other adds to the ambiguity of utterances in the absence of the contextual cues. In a virtual interaction, the absence of contextual cues is often ambiguous and not sufficiently reliable for first and second language learners to be able to make correct inferences. However, there are other certain responsibilities which e-learners should as well take in virtual environments. For instance, in a peer feedback task, now that there are no contextual cues, the learners should be responsive to the interlocutor's needs and employ a clear and informative style to get their messages across (Breuch, Racine, \& Lee, 2000). This means taking into account the special type of genre in which they are suggesting that students who are only linguistically present should use indexical devices such as page numbers, quotations, and paraphrases to make coherent evaluations and avoid ambiguities (Honeycutt, 2001).

A distinction is often made between synchronous and asynchronous online means. The former designates a condition which is closer to reality, that is, the two (or more) interlocutors are engaged in the conversation simultaneously, such as chat and web conferencing services; while the latter refers to offline ways of communication such as email, bulletin board, and so on. Research suggests that the synchronous ways of peer feedback are more effective (Honeycutt, 2001) because they, contrary to asynchronous means, do not reduce interactivity resulting from the lack of contextual cues and the delay of information (Braine, 2001; Liu \& Sadler, 2003; Tuzi, 2004). However, relying upon synchronous peer communication in general, and peer feedback in particular, is not always practical. Logistically speaking, the provision of a controlled synchronous communication is often difficult, and that it tend to be scattered, confusing, and disruptive (Braine, 2001; Honeycutt, 2001; Liu, \& Sadler, 2003). Alternatively, synchronous communication has been found to have less time pressure, be more serious (Honeycutt, 2001), and more effective. Besides, research suggests that another advantage of online asynchronous peer feedback is the possibility of a less stressful environment.

\section{Methodology}

\subsection{Participants}

There were 60 Iranian EFL learners who had been selected based non-random judgment sampling design. Each group consisted of 30 participants. They were second year BA students majoring in Teaching English as a Foreign Language (TEFL) at Islamic Azad University, Dezful Branch, and were required to take up and pass a writing course in their third semester. They ranged in age from 18 to 26 . The research sample consisted of both male and female learners.

\subsection{Instrumentation}

The course book was Paragraph Development: A Guide for Students of English developed by Arnaudet and Barret (1990) constituted the required text for the course. Using this text, the students were familiarized with different types of paragraphs and, following the models provided, were given hand-on practice to write. The book comprised of 8 chapters out of which the first 4 were taught.

A self- and peer-assessment scheme was made available to the students. The checklists (Bauch, 1997) provided a detailed way of writing self- and peer-assessment, also exhibiting some tips for the criteria ticked off by the participants.

\subsection{Procedure}

One week before the experiment, two EFL writing classes were selected from a whole-semester schedule. The two classes were treated under control and experimental conditions. The two groups were required to comment on their peers' writing pieces using the checklist to whom had been made available, but in different ways. To the experimental group, online peer feedback techniques were taught. That is, an internet group was started in which the students learnt how to submit their own posts and see the entries by their classmates. Of course, the submission of each post followed the usual classroom presentation of the corresponding lesson in the class materials. 
For the control group, the feedback mode was offline. That is, they went about the commenting process by photocopying their pieces and sharing with the class. They still used the same checklists and proceeded as they finished the materials in the class.

As the participants in each group were 30 in number, each student's commenting on 29 other pieces for 3 lessons sounded impractical. Therefore, the students were divided into 10 groups of 3 learners in each group, which made the process more manageable since now each group needed to evaluate 9 other works. The groups, then, were required to self-assess their own writing piece, which was a collaborative effort of the three members, and share it with the other groups, either in offline or online form and, subsequently, assess the other groups' works in light of the criteria in the checklist and let them know about their comments.

After three consecutive peer-feedback runs, tantamount to 3 units of the book, the research project finalized as the students were tested on their writing. Now, the individual students' performance was taken into account. The students were given one topic to write on. Afterwards, the writing pieces were checked against the criteria of the checklist by the two researchers. The performance of the two groups was, subsequently, compared using the t-test statistical analysis. Overall, the course continued for 1 semester, totaling 10 sessions of 90 minutes.

\section{Data Analysis}

Since the scoring of the writing pieces ran the risk of misjudgment on the part of the scorer, the instructor was also relied on for help. That is, both the researcher and the class instructor rated the pieces so that the average score could emerge. In order to carry out an inter-rater reliability, the Pearson Correlation formula was applied to the data presented in Table 1.

After obtaining two sets of scores on the performance of the two groups, a t-test statistical analysis was performed on the data to reveal whether the difference was of a significant nature. Comparing the means and standard deviations revealed a very small difference in the performance of offline peer-feedback condition $(M=14.63, S D=$ $2.41)$ and that of the online peer-feedback condition $(M=14.97, S D=2.41)$. However, the trend in the analysis indicated that no significant differences were found between the two groups, $t(58)=.564, p<.05$. The results are presented in Table 2.

According to table 2, the mean is 0.33 for both groups in which the standard deviation is 0.591 and confidence interval is $\% 95$ for the statistics of both groups which are (-.850 to 1.516); and t-test statistics is 0.564 to comparing t-test statistics and " $\mathrm{t}$ " which is received from the table, researcher would judge about the Null Hypothesis (HO1); but in an easier way SPSS software will present a significant level applying acceptance or rejection of the Null Hypothesis, that number which is presented in table 2 is 0.656 that shows at the confidence interval of $\% 5$ the Null Hypothesis cannot be rejected. The significant level of 0.656 indicates that at the confidence interval \%95 Null Hypothesis which shows the equality of the groups cannot be rejected.

\section{Conclusion}

Based on the gathered data, this study indicated that the writing performance of the two groups, online and offline was the same, and no significant differences were observed between the two groups. Therefore, the conclusion that online and offline modes of writing instruction does not significantly impact students' performance can crudely be drawn. However, taking account of the related literature in the field shows something more or less the same.

While both modes of synchronous and asynchronous presented EFL learners with opportunities to practice and expand their fluency in ways that differ from conventional oral and written classroom practices, not all students took advantage of this opportunity. In the asynchronous data examined the discourse functions identified were classified as student responses to teacher questions or prompts. Asynchronous discourse functions identified were similar to those found in traditional language classroom discourse (Tuzi, 2001).

Honeycutt (2001) showed that the synchronous ways of feedback are more effective; while, asynchronous means of online instruction do not reduce interactivity resulting from the lack of contextual cues and delay of information (Braine, 2001; Liu, \& Sadler, 2003; Tuzi, 2004). Asynchronous discussions in particular allow language learners more time to plan their writing, edit their spelling, grammar, and punctuation when paying attention to form, and make longer contributions than students composing synchronously. Learners are thus able to focus on both form and meaning to a greater extent than when they are engaged in rapid fire exchanges and socializing via synchronous discussions. However, relying upon synchronous peer communication in general, and peer feedback in particular, is not always practical. Logistically speaking, the provision of a controlled synchronous communication is often difficult, and such a medium tends to be scattered, confusing, and disruptive (Braine, 2001; Honeycutt, 2001; Liu, \& Sadler, 2003). Alternatively, asynchronous communication has been found to have less time pressure (Tannacito \& Tuzi, 2002), more serious (Honeycutt, 2001), and more effective (Walther, 1996). Besides, research suggests that 
another advantage of online asynchronous peer feedback is the possibility of a less stressful environment. Asynchronous mode is powerful tool that facilitate the creation of dynamic learning environments where language is used as a tool to brainstorm, disseminate information, analyze text as it is produced, take linguistic risks, and challenge other views without fear of overt intimidation by bullies or egotists who often interrupt the most and speak the loudest in face-to-face discussions and traditional classroom settings (Tuzi, 2004).

The fact that the two modes of instruction here provided similar outcomes confirms the effectiveness of the offline way of instruction which has been used so far. Not long has it been since the web technology has catered for asynchronous ways of online instruction; while, offline traditional classrooms have always had a permanent place in the teaching and learning profession. Besides, this study pointed to an alternative to the usual face-to-face classrooms.

\section{References}

Arnaudet. M. L., \& Barrett. M. E. (1990). Paragraph Development. London: Published Pearson Education.

Bauch, S. (1997). Seeing students as writers. In B. Bruce, J.K. Peyton, \& T. Batson (Eds.). Network Based Classrooms (pp. 138-160). Cambridge, MA: Cambridge University Press.

Box, S. (2003). CALL: Past, present and future. System, 13, 13-48

Braine, G. (2001). A study of English as foreign language (EFL) writers on a local area network (LAN) and in traditional classes. Computers and Composition, 18, 275-292.

Breuch, M. K, Racine S.J, \& Lee, A. (2000) Developing sound tutor training for online writing centers: Creating productive peer reviewers. Computers and Composition 17, 245-263.

Chapelle, C.A. (2003). English language learning and technology: lectures on applied linguists in the age of information technology. Amsterdam: John Benjamins Publishing Company.

Honeycutt, L. (2001). Comparing e-mail and synchronous conferencing in online electronic versus traditional modes o writing. Journal of English for Academic Purposes, 193_227.

Jones, A. H. (2000). Editor's preface: Teaching portfolio in teacher education. Teacher Education Quarterly, 25 (1), p.3.

Kemp, F. (2003). The importance of peer interactivity in writing instruction. [Online] Available: http://www.sciencedirect.com/science (July 16, 2006)

Liu, J., \& Sadler, R. W. (2003). The effect and affect of peer review in electronic versus traditional modes on L2 writing. Journal of English for Academic Purposes, 2(3), 193-227.

Tannacito, T., \& Tuzi, F. T. (2002). A comparison of e-response. Two experiences, one conclusion. Karros, 7(3), 1-14. [Online] Available: www.sciencedirect.com (July 25, 2006)

Tuzi, F. T. (2004). The impact of e-feedback on the revision of L2 writers in an academic writing course. Computers and Composition, 21, 217-235.

Walther, J. B. (1996). Computer- mediated communication: impersonal and hyper personal interaction. Communication Research, 23, 3-43.

Table1. Inter-rater Reliability

\begin{tabular}{|ll|l|l|}
\hline & RATER 1 & RATER 2 \\
\hline RATER 1 & Person Correlation & 1 & $.778^{* *}$ \\
& Sig.(2-tailed) &. & .000 \\
& $\mathrm{~N}$ & 60 & 60 \\
\hline RATER 2 & Person Correlation & .778 & 1 \\
& Sig.(2-tailed) & .000 &. \\
& $\mathrm{~N}$ & 60 & 60 \\
\hline
\end{tabular}

**.Correction is significant at the 0.01 level (2-tailed)

As can be seen, the inter-rater reliability of the raters' judgment was .77, which is a high amount of correlation. 
Table 2. Results of Independent Samples T-Test on the Scores

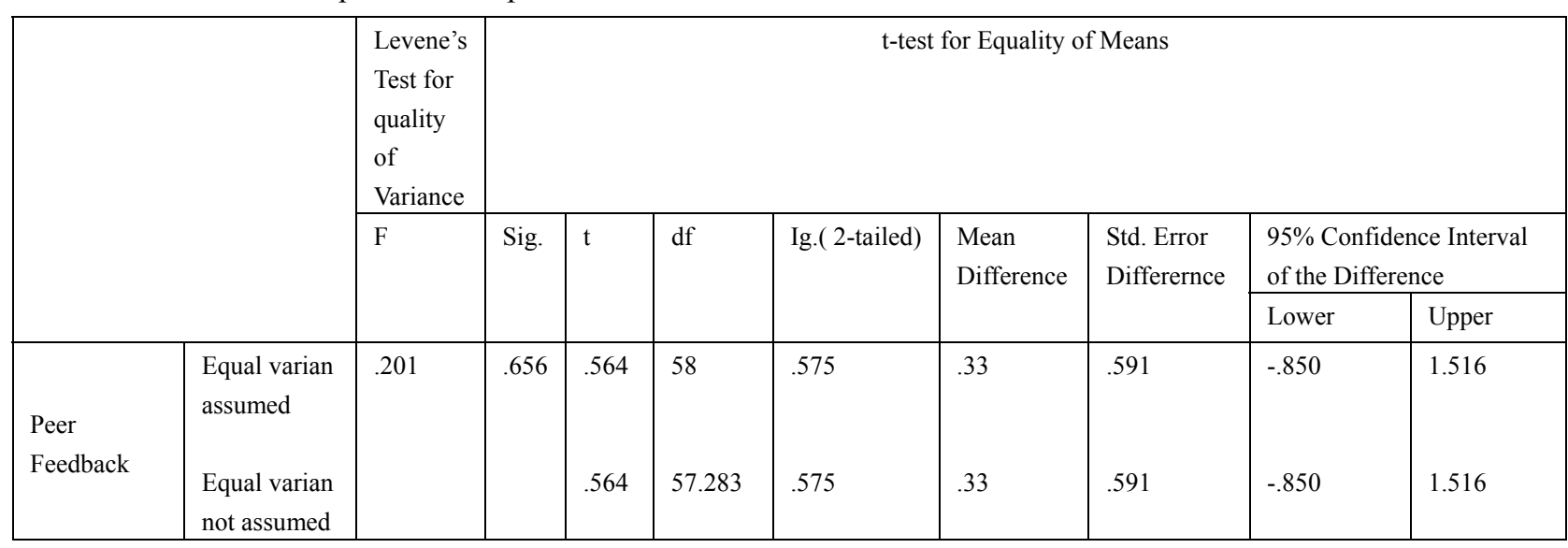

As can be seen, the results indicated that the two groups were statistically similar. 